\title{
Emancipation of the voice: Vocal complexity as a fitness indicator
}

\author{
John L. Locke ${ }^{1}$
}

Published online: 18 July 2016

(C) Psychonomic Society, Inc. 2016

\begin{abstract}
Although language is generally spoken, most evolutionary proposals say little about any changes that may have induced vocal control. Here I suggest that the interaction of two changes in our species - one in sociality, the other in life history-liberated the voice from its affective moorings, enabling it to serve as a fitness cue or signal. The modification of life history increased the helplessness of infants, thus their competition for care, pressuring them to emit, and parents (and others) to evaluate, new vocal cues in bids for attention. This change elaborated and formalized the care communication system that was used in infancy and, because of parental adoption of social criteria, extended it into childhood, supporting the extrafamilial relationships that intensify in those stages. The remodeling of life history, in conjunction with intensified sociality, also enhanced vocal signaling in adolescence - a second stage that is unique to humans - and adulthood. Building on the new vocal skills and fitness criteria that emerged earlier, I claim that males with ornamented speech enjoyed advantages in their pursuit of dominance and reproductive opportunities in evolutionary history, as they do today. There are implications of this scenario for the mechanistic level of vocal diversification. Today, intentionality plays a role both in the instrumental crying of infants and the modulated vocalizations of adults. In evolutionary history, I claim that in both cases, spontaneously emitted behavioral cues elicited perceptible responses, giving rise to strategic signals that
\end{abstract}

John L. Locke

John.locke@lehman.cuny.edu

1 Lehman College, City University of New York, 217 Speech and Theatre Building, 250 Bedford Park Blvd. West, New York, NY 10019, USA were sent, and processed, under a new and fundamentally different neural regime.

Keywords Animal social learning · Comparative psychology $\cdot$ Phonology $\cdot$ Speech production

We cannot achieve a satisfying proposal on the evolution of language, which is generally spoken, without explaining how it became possible for our ancestors to use their voices flexibly and creatively, thus to make the kinds of sounds that, with other changes, would have allowed them to communicate symbolically (Fitch, 2000). This capability presumably emerged before, not after, the appearance of language (Darwin, 1871). But what would a wordless use of the modulated voice have done for our prelinguistic ancestors? I will suggest that the voice both cued and signaled fitness qualities because of something attractive or informative about its physical form.

There is a lot of theoretical work to do here because chimpanzees, codescendants of our last common ancestor, tend not to vocalize flexibly or creatively, to invent new vocalizations, or to combine calls to convey new "meanings" (Fischer, Wheeler, \& Higham, 2015; Zuberbühler, 2003). This leaves us with an important question: How did our ancestors acquire the diverse and flexible production capacity of modern humans? In stressing the role of production, of course, we must not neglect the evaluative role of receivers. An increase in diversity or attractiveness may have been driven by a change in the perceptual or evaluative systems of receivers who were motivated by new social pressures to make finer distinctions regarding fitness (Guilford \& Dawkins, 1991).

One hypothesis is that the vocal logjam was broken by a huge expansion in the size of human groups, producing new social challenges that required more complex ways of 
signaling (Humphrey, 1976; Jolly, 1976; also see Freeberg, Dunbar, \& Ord, 2012). This may have played a major role, but individuals must have begun to diversify and control vocal behavior in specific situations. I will claim that changes in sociality, in conjunction with modifications of life history, combined to liberate and diversify vocalization in two important contexts.

\section{Infancy and childcare}

The first proposal relates to infancy. Most evolutionary proposals say little about this stage, but no account can be complete without identifying the environmental changes that produced relevant traits in development and the reasons why the new traits would have conferred contemporaneous reproductive advantages. Nearly a century ago, Walter Garstang (1922) spoke of the "absurdity" of supposing that a new trait could evolve in mature members of the species, a judgment that has been repeatedly confirmed in the interim (Gould, 1977; Hall, 2002; Northcutt, 1990; West-Eberhard, 2003).

The context is care. Changes in life history left the human infant unusually helpless - unable to survive without an intensification and extension of care (Bogin, 1999; Falk, 2004). A second change, earlier weaning, reduced infancy from 5 years - the duration of chimpanzee weaning - to three, producing a short childhood (Locke \& Bogin, 2006). This also truncated the period of maternal lactation, which reduced the interbirth interval. The resulting increase in equally dependent siblings could only have stiffened competition for care (Bogin, 1999; Locke \& Bogin, 2006). These changes, I suggest, encouraged infants to look for new ways to attract attention, and caregivers to unconsciously search for indications that their offspring's development was developing apace.

The increasing altriciality of human infants may also have encouraged parents to adopt cooperative breeding, parental sharing of care with relatives and others (Hrdy, 1999, 2004). In cooperative breeding arrangements, individuals who are less genetically related to the infant than his or her own parents may be less motivated to provide care. Here I would note that nestling birds that are genetically unrelated to prospective caregivers beg more loudly than others (Briskie, Naugler, \& Leech, 1994), and human infants raised by step- or alloparents may try harder, or operate more strategically, to get the care they need (Locke, 2006).

\section{The first negotiation}

In the early 1970s, Trivers $(1972,1974)$ described a basic dilemma in the rearing of the young: a conflict between the needs of parents and their dependent offspring. On the one hand, the necessity of feeding and protecting their infants requires parents to monitor their offspring's behavior for signs that attention is required. But parents have competing responsibilities, including the management of other children. Parents thus look for opportunities to withdraw care, and infants attempt to prevent this with increasingly clever bids for attention, and by monitoring parental responses to these behaviors. It is assumed that selection would have operated on both the infant's use of, and the parents' response to, behaviors that signaled infants' needs. Today, a female advantage in the appraisal of vocal or facial affect, where it occurs, is occasionally attributed to evolutionary pressure to detect subtle changes in infant signals (Babchuk, Hames, \& Thompson, 1985; Hampson, van Anders, \& Mullin, 2006).

Crying reliably elicits care, and it carries transient information about the infant's physical and emotional state. If noxious or inconsolable, crying can elevate the stress level of caregivers (Zeskind \& Collins, 1987; Out, Pieper, BakermansKranenburg, Zeskind, \& IJzendoorn, 2010) and lead to abuse (Frodi, 1985; Locke, 2006). Crying also carries information about health conditions. It has long been known that the crying of healthy infants can be acoustically discriminated from the crying of infants with low birth weight; metabolic, chromosomal, and endocrine disorders; and brain damage (Michelsson, 1986; Wolff, 1969).

But if human societies enlarged, were there parallel changes in the criteria parents and alloparents used in allocating attention? It is generally agreed that increases in group size ramped up levels of social competition and cooperation. What was at stake, often, was access to social capital- the knowledge, goods, and services that members of alliances and reciprocal friendships trade with each other. But these social arrangements are not automatic: they must be negotiated. Thus, as the young develop, parental criteria for continuing attention would be expected to shift from physical well-being to abilities in the social domain: infants most likely to receive extended care and instruction would be those who display the ability to attract and engage with others - early signs of the ability to negotiate.

This may have been what Trivers (1974) had in mind when he pointed out that infants may employ "psychological weapons" to keep their parents from withdrawing care. A potentially important weapon is instrumental crying. In his observations of crying, Wolff (1969) noticed that as early as the third week of life, many infants produce "fake" cries, presumably based on an earlier discovery that their genuine cries elicited care. Wolff also noticed that first-time mothers were more likely to respond to cries than multiparous mothers.

These observations suggest that, with experience, mothers may learn to discriminate honest crying from the false cries of infants who want attention, but are not truly distressed. Because infants are the only ones who know whether they are "faking," parents must learn to interpret these careelicitation signals. Selection favors parental ability to discriminate honest from dishonest signals, driving infants to produce 
even more convincing signs that they are worth continuing care. Having been submitted to conscious control, the infant's signals can then be used in other contexts.

In the seventh month, crying typically subsides and a different form of vocalization appears (Koopmans-van Beinum \& van der Stelt, 1986) — one that has the opposite effect on caregivers and may have furthered the emancipation of vocal behavior from subcortical control (Myers, 1976): It is babbling, the production of well-formed syllables that parents frequently hear as speech. Initially, babbled sounds appear as fairly precise reduplications of apical stops (e.g., "da-da-da"), but in succeeding months the place of articulation and other phonetic features diversify. It has been speculated that the rapid and controlled shifting from sound to sound that occurs in variegated babbling "decouples" speech from more reflexive and prosodic vocal activity (Oller, 2000, 2004; also see Locke, 2004a).

Studies indicate that infants who produce a high rate of syllables per utterance are considered more pleasant, friendly, and likeable than infants who vocalize less complexly (Bloom, D’Odorico, \& Beaumont, 1993; Bloom \& Lo, 1990). When infants invent and use novel phonetic forms it appears to please parents, who incorporate them into their own speech. This tendency, which I have called "trickle up phonetics," may have contributed to the universal pattern whereby "baby words," like babbled utterances, are almost exclusively composed of reduplicated CV syllables, such as "dada" (or "papa") and "mama” (Locke, 1990, 2004b).

To some degree, babbling may have persuaded parents that their offspring were physically fit, for the timely onset of babbling implies normal auditory sensation (Oller \& Eilers, 1988) and the development of left-hemisphere control of fine motor movement (Locke, Bekken, McMinn-Larson, \& Wein, 1995). There is evidence, too, that infants who are neurologically impaired or intellectually disabled are less likely to begin producing complex (syllabic) vocalization at the neurotypical age than their typically developing peers (Cobo-Lewis, Oller, Lynch, \& Levine, 1996; Oller, Eilers, Neal, \& Cobo-Lewis, 1998). Because there is continuity between babbling and speech, it is not surprising that strong positive correlations have been obtained between quantity and quality of vocalization in infancy and measures of intelligence in later stages of life history, including adulthood (Cameron, Livson, \& Bayley, 1967).

If they were to thrive under conditions of increased competition, individuals would be expected to show promise of social ability in infancy. Today, decisions about care are also based on the infant's ability to initiate and respond to social stimulation. This may have contributed to an extension of care into childhood. In fact, childhood itself may have been expanded to its present (4-year) length because parents needed to provide their outward-bound offspring with reliable information about how to deal with an increasingly complex social environment (Fitch, 2004, 2007), one that contained individuals of unknown intentions.

What I am suggesting is this: As reproductive fitness increasingly presupposed the ability to negotiate social relationships and social capital - an indirect effect of large group living - parents may well have ramped up their search for signs that offspring were attempting to engage with them in an attempt to negotiate continuing attention, including instruction. What would have been needed in our steadily socializing species was a more flexible and playful form of vocalization that would engage, possibly even entertain, parents who were looking for signs that their infant would eventually be able to develop and maintain friendships, interpret intentions, and do all the other things that cooperation and competition require. My claim is that infants who vocalized playfully and creatively received continuing care from their parents, whose perceptual and evaluative criteria were also becoming more finely tuned, and more socially and psychologically oriented.

If social negotiations presuppose one's ability to send and interpret social signals, they also reflect the ability to interact. In the 1970s, Daniel Stern studied 3- to 4-month-olds in interaction with their mothers. He found that when these dyads were positively aroused emotionally, they vocalized together and appeared to get a great deal of enjoyment from it. He called these episodes "coactional vocalizations," early attachment behaviors that seemed to contribute to the formation of mother-infant bonds (Stern, Jaffe, Beebe, \& Bennett, 1975). Since then, it has been found that vocal and other types of mimicry (and synchrony) facilitate emotional and social relationships (Carpenter, Uebel, \& Tomasello, 2013; Cirelli, Einarson, \& Trainor, 2014; Cirelli, Wan, \& Trainor, 2014).

\section{Mate selection}

If, in evolution, selection acted on traits that were already present in some form, increased vocal ability emerging from infancy and childhood may have been appropriated and refined for new applications that arose in juvenility and adolescence. In songbirds, several studies have witnessed an association between song complexity and learning proficiencymales with more song phrase elements requiring fewer learning trials to solve a novel foraging task (Boogert, Giraldeau, \& Lefebvre, 2008; Cauchard, Boogert, Lefebvre, Dubois, \& Doligez, 2013).

In a reproductive context, there is evidence that females use accuracy of song learning by males as an honest cue to developmental history, thus to quality (Lachlan \& Nowicki, 2012; Nowicki \& Searcy, 2011). In one study, it was found that songs learned by well-nourished male swamp sparrows elicited significantly higher levels of courtship display from females than the songs that had been learned by undernourished male swamp sparrows. Songs of the properly nourished males were longer 
and displayed a higher trill rate, greater stereotypy, and more notes per syllable (Searcy, Peters, Kipper, \& Nowicki, 2010).

There may also be a link between signal complexity and mating success in primates. In gelada monkeys, groups may contain over a thousand individuals and a number of tiny reproductive units under the control of male "leaders." It was reported recently that males display significantly more complex vocalizations than do females (Gustison, le Roux, \& Bergman, 2012), and in playback experiments, female geladas displayed a preference for these more complex vocalizations (Gustison \& Bergman, 2016).

Do displays of complex behaviors play a role in human mating? In a study of instrumental music-piano compositions-Charlton (2014) reported that young women preferred, as short-term sexual partners, men who had composed more rather than less complex music at precisely the interval in their menstrual cycle when conception risk was highest. How do young women feel about vocal complexity?

First, it needs to be acknowledged that something about the speaking voice - its pitch — plays a key role in the evaluation of fitness. Men with low-pitched voices have relatively higher amounts of testosterone and are typically judged by female listeners to be more dominant and attractive (Collins, 2000; Feinberg et al., 2005; Puts, Gaulin, \& Verdolini, 2006), and there is evidence that women prefer low-pitched male voices, especially when they hear them in a courtship or mating context (Apicella \& Feinberg, 2009; Little, Connely, Feinberg, Jones, \& Roberts, 2011). This preference is stronger when women are in the fertile phase of their ovulatory cycle and estrogen levels are unusually high (Feinberg et al., 2006; Puts, 2005). Predictably, lower voice pitch predicts the mating success of males (Apicella, Feinberg, \& Marlowe, 2007).

An important transition in the evolution of vocal control may be linked to the distinction between cues and signals. A cue - some physical or behavioral feature that is informative - can evolve into a signal if its reproductive value is actively displayed (Maynard Smith \& Harper, 1995). The voice is a reproductive cue when it varies with sex hormone levels, but it can also be a reproductive signal. It has been reported that men may lower their pitch, and women may raise theirs, in a contrived mating context (Fraccaro et al., 2011; Puts et al., 2006; see discussion in Pisanski, Cartei, McGettigan, Raine, \& Reby, 2016).

What about vocal complexity - in the form of speech? Men with novel, extensive, or intricate vocal repertoires tend to dominate other men, and to enjoy unusual access to sex (Locke, 2001, 2008). Is this simply a correlation, or do men consciously or unconsciously diversify or ornament their utterances when it would increase their perceived fitness to do so?

There are indications that they do. In one study, young men defined contrived word combinations far more creatively when tested by an attractive young woman, or in competition with other men (Franks \& Rigby, 2005). In another study, it was found that young men used more low-frequency words following an imaginary assignation with a younger than with an older female, or an imaginary liaison with a male (Rosenberg \& Tunney, 2008). In a third study, subjects preferred an actor with attractive ways of speaking, both in the context of short- and long-term mating, based on lexical diversity, grammatical complexity, and verbal fluency (Lange, Zaretsky, Schwarz, \& Euler, 2014).

\section{Concluding remarks}

Because languages are universally spoken, it is incumbent on evolutionary theorists to identify specific pressures that induced the vocal and phonetic skill that was required to speak. My hypothesis is that the ability to generate attractive strings of vocal and phonetic material first cued, then signaled, physical and psychological fitness in infancy; and when human societies enlarged, that the young benefitted additionally if they displayed the vocal skills needed to negotiate social relationships. These abilities would surely have produced changes at the neural level of vocal control, for intentionality plays a critical role both in the concept of instrumental crying and modulated vocalization.

I want to close with an anecdote that may be instructive. In 1783, Chrisfrid Ganander described an ancestral Finnish tradition in which fathers used riddles to test "the acuity, intelligence and skills" of their daughters' suitors. When a young man sought romantic commitment, "three or more riddles were posed to him, to test his mind with them," wrote Ganander, "and if he could answer and interpret them, he received the girl, otherwise not" (Maranda, 1976, p. 127). Ganander's anecdote relates to the role of a parent in mate selection, but I see no reason why parents, aware that their offspring would ultimately be appraised on the basis of their social intelligence, might not have posed similar tests - ones that involved their offspring's ability to demonstrate or respond to vocal complexity, working much like a vocal riddle.

\section{References}

Apicella, C.L., \& Feinberg, D. R. (2009). Voice pitch alters mate-choicerelevnt perception in huntergatherers. Proceedings of the Royal Society of London B, 276, 1077-1082.

Apicella, C. L., Feinberg, D. R., \& Marlowe, F. W. (2007). Voice pitch predicts reproductive success in male hunter-gatherers. Biology Letters, 3, 682-684.

Babchuk, W. A., Hames, R. B., \& Thompson, R. A. (1985). Sex differences in the recognition of infant facial expressions of emotion: The primary caretaker hypothesis. Ethology and Sociobiology, 6, 89101.

Bloom, K., D’Odorico, L., \& Beaumont, S. (1993). Adult preferences for syllabic vocalizations: Generalizations to parity and native language. Infant Behavior \& Development, 16, 109-120. 
Bloom, K., \& Lo, E. (1990). Adult perceptions of vocalizing infants. Infant Behavior \& Development, 13, 209-219.

Bogin, B. (1999). Patterns of human growth (2nd ed.). New York: Cambridge University Press.

Boogert, N. J., Giraldeau, L.-A., \& Lefebvre, L. (2008). Song complexity correlates with learning ability in zebra finch males. Animal Behaviour, 76, 1735-1741.

Briskie, J. V., Naugler, C. T., \& Leech, S. M. (1994). Begging intensity of nestling birds varies with sibling relatedness. Proceedings of the Royal Society of London B, 258, 73-78.

Cameron, J., Livson, N., \& Bayley, N. (1967). Infant vocalizations and their relationship to mature intelligence. Science, 157, 331-333.

Carpenter, M., Uebel, J., \& Tomasello, M. (2013). Being mimicked increases prosocial behavior in 18-month-old infants. Child Development, 84, 1511-1518.

Cauchard, L., Boogert, N. J., Lefebvre, L., Dubois, F., \& Doligez, B. (2013). Problem-solving performance is correlated with reproductive success in a wild bird population. Animal Behaviour, 85, 19-26.

Charlton, B. D. (2014). Menstrual cycle phase alters women's sexual preferences for composers of more complex music. Proceedings of the Royal Society B, 281, 20140403.

Cirelli, L. K., Einarson, K. M., \& Trainor, L. J. (2014). Interpersonal synchrony increases prosocial behavior in infants. Developmental Science, 369. doi:10.1111/desc.12193

Cirelli, L. K., Wan, S. J., \& Trainor, L. J. (2014). Fourteen-month-old infants use interpersonal synchrony as a cue to direct helpfulness. Philosophical Transactions of the Royal Society B, 369. doi:10.1098 rstb.2013.0400

Cobo-Lewis, A., Oller, D. K., Lynch, M. P., \& Levine, S. L. (1996). Relations of motor and vocal milestones in typically developing infants and infants with Down syndrome. American Journal on Mental Retardation, 100, 456-467.

Collins, S.A. (2000). Men's voices and women's choices. Animal Behaviour, 60, 773-780.

Darwin, C. (1871). The descent of man and selection in relation to sex. London: Murray.

Falk, D. (2004). Prelinguistic evolution in early hominins: whence motherese? Behavioral and Brain Sciences, 27, 491-541.

Feinberg, D. R., Jones, B. C., DeBruine, L. M., Moore, F. R., Smith, M. J. L., Cornwell, E. R., \& Perrett, D. I. (2005). The voice and face of woman: One ornament that signals quality? Evolution and Human Behavior, 26, 398-408.

Feinberg, D.R., Jones, B. C., Law Smith, M. J., Moore, F. R., \& DeBruine, L. M. (2006). Menstrual cycle, trait estrogen level, and masculiity preferences in the human voice. Hormones and Behavior, 49, 215-222.

Fischer, J., Wheeler, B. C., \& Higham, J. P. (2015). Is there any evidence for vocal learning in chimpanzee food calls? Current Biology, 25, $1028-1029$

Fitch, W. T. (2000). The evolution of speech: A comparative review. Trends in Cognitive Science, 4, 258-267.

Fitch, W. T. (2004). Kin selection and "mother tongues": A neglected component in language evolution. In D. K. Oller \& U. Griebel (Eds.), The evolution of communication systems: A comparative approach (pp. 275-296). Cambridge: MIT Press.

Fitch, W. T. (2007). Evolving meaning: The roles of kin selection, allomothering and paternal care in language evolution. In C. Lyon, C. Nehaniv, \& A. Cangelosi (Eds.), Emergence of communication and language (pp. 29-51). New York: Springer.

Fraccaro, P. J., Jones, B. C., Vukovic, J., Smith, F. G., Watkins, C. D., Feinberg, D. R., ... DeBruine, L. M. (2011). Experimental evidence that women speak in a higher voice pitch to men they find attractive. Journal of Evolutionary Psychology, 9, 57-67.

Franks, B. K., \& Rigby, K. (2005). Deception and mate selection: Some implications for relevance and the evolution of language. In M.
Tallerman (Ed.), Language origins: Perspectives on evolution (pp. 185-208). Oxford: Oxford University Press.

Freeberg, T. M., Dunbar, R. I. M., \& Ord, T. J. (2012). Social complexity as a proximate and ultimate factor in communicative complexity. Philosophical Transactions of the Royal Society B, 367, 1785-1801.

Frodi, A. (1985). When empathy fails: Aversive infant crying and child abuse. In B. M. Lester \& C. F. Z. Boukydis (Eds.), Infant crying: Theoretical and research perspectives (pp. 263-277). New York: Plenum Press.

Garstang, W. (1922). The theory of recapitulation: A critical re-statement of the biogenetic law. Journal of the Linnaean Society (Zoology), 35 , 81-101.

Gould, S. J. (1977). Ontogeny and phylogeny. Cambridge: Harvard University Press.

Guilford, T., \& Dawkins, M. S. (1991). Receiver psychology and the evolution of animal signals. Animal Behaviour, 42, 1-14.

Gustison, M. L., \& Bergman, T. J. (2016). Vocal complexity influences female responses to gelada male calls. Scientific Reports, 6, 19680. doi:10.1038/srep19680

Gustison, M. L., le Roux, A., \& Bergman, T. J. (2012). Derived vocalizations of geladas (Theropithecus gelada) and the evolution of vocal complexity in primates. Philosophical Transactions of the Royal Society B, 367, 1847-1859.

Hall, B. K. (2002). Evolutionary developmental biology. In N. MinughPurvis \& K. J. McNamara (Eds.), Human evolution through developmental change (pp. 7-27). Baltimore: Johns Hopkins University Press.

Hampson, E., van Anders, S. M., \& Mullin, L. I. (2006). A female advantage in the recognition of emotional facial expressions: Test of an evolutionary hypothesis. Evolution and Human Behavior, 27, 401416.

Hrdy, S. B. (1999). Mother nature: Natural selection and the female of the species. London: Chatto \& Windus.

Hrdy, S. B. (2004). Comes the child before man: How cooperative breeding and prolonged postweaning dependence shaped human potentials. In B. Hewlett \& M. Lamb (Eds.), Hunter-gatherer childhoods: Evolutionary, developmental and cultural perspectives, 65-91. New Brunswick, NJ: Aldine Transactions.

Humphrey, N. (1976). The social function of intellect. In P. P. G. Bateson \& R. A. Hinde (Eds.), Growing points in ethology. Cambridge: Cambridge University Press.

Jolly, A. (1976). Lemur social behavior and primate intelligence. Science, 153, 501-506.

Koopmans-van Beinum, F. J., \& van der Stelt, J. M. (1986). Early stages in the development of speech movements. In B. Lindblom \& R. Zetterstrom (Eds.), Precursors of early speech. New York: Stockton Press.

Lachlan, R. F., \& Nowicki, S. (2012). How reliable is song learning accuracy as a signal of male early condition? American Naturalist, 180, 751-761.

Lange, B. P., Zaretsky, E., Schwarz, S., \& Euler, H. A. (2014). Words won't fail: Experimental evidence on the role of verbal proficiency in mate choice. Journal of Language and Social Psychology, 33, 482-499.

Little, A. C., Connely, J., Feinberg, D. R., Jones, B. C., \& Roberts, S. C. (2011). Human preference for masculinity differs according to context in faces, bodies, voices, and smell. Behavioral Ecology, 22, 862-868.

Locke, J. L. (1990). "Mama" and "papa" in child language: Parent reference or phonetic preference? In B. Metuzale-Kangere \& H. D. Rinholm (Eds.), Symposium Balticum: A Festschrift to honour Professor Velta Ruke-Dravina. Hamburg: Helmut Buske Verlag.

Locke, J. L. (2001). Rank and relationships in the evolution of spoken language. Journal of the Royal Anthropological Institute, 7, 37-50.

Locke, J. L. (2004a). How do infants come to control the organs of speech? In B. Maassen, R. D. Kent, H. F. M. Peters, P. H. H. M. 
van Lieshout, \& W. Hulstijn (Eds.), Speech motor control in normal and disordered speech. Oxford: Oxford University Press.

Locke, J. L. (2004b). Trickle up phonetics: A vocal role for the infant. Behavioral and Brain Sciences, 27, 516.

Locke, J. L. (2006). Parental selection of vocal behavior: Crying, cooing, babbling and the evolution of spoken language. Human Nature, 17, $155-168$.

Locke, J. L. (2008). Cost and complexity: Selection for speech and language. Journal of Theoretical Biology, 251, 640-652.

Locke, J. L., Bekken, K. E., McMinn-Larson, L., \& Wein, D. (1995). Emergent control of manual and vocal-motor activity in relation to the development of speech. Brain and Language, 51, 498-508.

Locke, J. L., \& Bogin, B. (2006). Language and life history: A new perspective on the evolution and development of linguistic communication. The Behavioral and Brain Sciences, 29, 259-325.

Maranda, E. K. (1976). Riddles and riddling: An introduction. Journal of American Folklore, 89, 127-137.

Maynard Smith, J., \& Harper, D. G. C. (1995). Animal signals: Models and terminology. Journal of Theoretical Biology, 177, 305-311.

Michelsson, K. (1986). Cry analysis in clinical neonatal diagnosis. In B. Lindblom \& R. Zetterstrom (Eds.), Precursors of early speech. New York: Stockton Press.

Myers, R. E. (1976). Comparative neurology of vocalization and speech: Proof of a dichotomy. Annals of the New York Academy of Sciences, 280, 745-757.

Northcutt, R. G. (1990). Ontogeny and phylogeny: A re-evaluation of conceptual relationships and some applications. Brain, Behavior and Evolution, 36, 116-140.

Nowicki, S., \& Searcy, W. A. (2011). Are better singers smarter? Behavioral Ecology, 22, 10-11.

Oller, D. K. (2000). The emergence of the speech capacity. Mahwah: Erlbaum.

Oller, D. K. (2004). Underpinnings of a theory of communicative evolution. In D. K. Oller \& U. Griebel (Eds.), Evolution of communication systems: A comparative approach. Cambridge: MIT Press.

Oller, D. K., \& Eilers, R. E. (1988). The role of audition in infant babbling. Child Development, 59, 441-449.

Oller, D. K., Eilers, R. E., Neal, A. R., \& Cobo-Lewis, A. (1998). Late onset canonical babbling: A possible early marker of abnormal development. American Journal on Mental Retardation, 103, 249263.

Out, D., Pieper, S., Bakermans-Kranenburg, M. J., Zeskind, P. S., \& IJzendoorn, M. H. (2010). Intended sensitive and harsh caregiving responses to infant crying: The role of cry pitch and perceived urgency in an adult twin sample. Child Abuse \& Neglect, 34, 863-873.

Pisanski, K., Cartei, V., McGettigan, C., Raine, J., \& Reby, D. (2016). Voice modulation: a window into the origins of human vocal control? Trends in Cognitive Science, 20, 304-319.

Puts, D. A. (2005). Mating context and menstrual cycle phase affect women's preferences for male voice pitch. Evolution and Human Behavior, 26, 388-397.

Puts, D. A., Gaulin, S. J. C., \& Verdolini, K. (2006). Dominance and the evolution of sexual dimorphism in human voice pitch. Evolution and Human Behavior, 27, 283-296.

Rosenberg, J., \& Tunney, R. J. (2008). Human vocabulary use as display. Evolutionary Psychology, 6, 538-549.

Searcy, W. A., Peters, S., Kipper, S., \& Nowicki, S. (2010). Female response to song reflects male developmental history in swamp sparrows. Behavioral Ecology and Sociobiology, 64, 1343-1349.

Stern, D. N., Jaffe, J., Beebe, B., \& Bennett, S. L. (1975). Vocalizing in unison and in alternation: Two modes of communication within the mother-infant dyad. Annals of the New York Academy of Sciences, $263,89-100$.

Trivers, R. L. (1972). Parental investment and sexual selection. In B. Campbell (Ed.), Sexual selection and the descent of man (pp. 1871-1971). Chicago: Aldine-Atherton.

Trivers, R. L. (1974). Parent-offspring conflict. American Zoologist, 14 249-264.

West-Eberhard, M. J. (2003). Developmental plasticity and evolution. Oxford: Oxford University Press.

Wolff, P. (1969). The natural history of crying and other vocalizations in early infancy. In B. M. Foss (Ed.), Determinants of infant behaviour (Vol. 4). London: Methuen.

Zeskind, P. S., \& Collins, V. (1987). Pitch of infant crying and caregiver responses in a natural setting. Infant Behavior \& Development, 10, 501-504.

Zuberbühler, K. (2003). Referential signaling in non-human primates: Cognitive precursors and limitation for the evolution of language. Advances in the Study of Behaviour, 33, 265-307. 